\title{
Macrophage Phenotype and Renal Fibrosis in Obstructive Nephropathy
}

\author{
Masashi Nishida Kenji Hamaoka \\ Department of Pediatric Cardiology and Nephrology, Kyoto Prefectural University of Medicine, \\ Graduate School of Medical Science, Kyoto, Japan
}

\section{Key Words}

Classically activated macrophage $\cdot$ Alternatively activated macrophage

\begin{abstract}
Macrophages have classically been recognized as key players that may promote renal fibrosis. However, several recent studies have suggested a beneficial anti-fibrotic role of infiltrating macrophages that acts to preserve renal architecture in the progressive renal scarring associated with obstructive nephropathy. Furthermore, recent investigations indicate a role for macrophages in both inflammation and repair during disease processes and this has superseded the classical injurious view of macrophages. As a result, the exact role of interstitial macrophages upon various facets of renal fibrosis is an important challenge that needs to be addressed. In this article, we discuss the possible beneficial anti-fibrotic role of infiltrating macrophages in obstructive nephropathy and discuss the potential mechanisms that may regulate the effect of macrophages upon renal interstitial fibrosis.
\end{abstract}

Copyright $\odot 2008$ S. Karger AG, Basel

\section{Introduction}

Chronic tubulointerstitial inflammation and subsequent fibrosis form a final common pathway that leads to progressive loss of renal function in various chronic kidney diseases. Tubulointerstitial disease is characterized

\section{KARGER}

Fax +4161306 1234 E-Mail karger@karger.ch www.karger.com (c) 2008 S. Karger AG, Basel

$1660-2129 / 08 / 1101-0031 \$ 24.50 / 0$

Accessible online at:

www.karger.com/nee by early inflammatory cell infiltration followed by peritubular capillary loss and tubular atrophy. Cells of the monocyte/macrophage lineage are always present and are often the predominant infiltrating cell type in both experimental models and human renal disease. Since the presence of macrophages often correlates with the degree of renal fibrosis, the infiltrating macrophage has been considered to be a key player that actively promotes fibrosis [1].

Many of the cellular and molecular events underlying interstitial fibrosis have been elucidated in the past 5 years with many processes studied in the model of unilateral ureteral obstruction (UUO) that is a well-established model of progressive renal interstitial fibrosis. UUO is a useful model as it results in many pathophysiological events within 1 week following ureteral ligation that encompass many aspects of other kidney disease models related to interstitial fibrosis. Interstitial macrophage infiltration is evident soon after ureteral ligation [2] and is recognized as playing a central role in the inflammatory response and subsequent progression of interstitial fibrosis. This notion was primarily attributed to previous studies in which experimental manipulations that decreased the number of interstitial macrophages preserved renal architecture. However, several recent studies have suggested a beneficial anti-fibrotic role of infiltrating macrophages in some settings of obstructive nephropathy [3-8]. Furthermore, recent investigations have highlighted new roles for macrophages in the biology of inflammation and fibrosis and extended the role 
of macrophages in both inflammation and tissue repair [9-11]. In this review, we focus upon the potential antifibrotic actions of infiltrating macrophages in UUO and discuss the possible regulatory role of macrophages in renal interstitial fibrosis.

\section{Macrophage Infiltration after UUO}

An increase in the number of interstitial macrophages is evident $4 \mathrm{~h}$ after ureteral ligation. Interstitial macrophage number increases rapidly in the first $24 \mathrm{~h}$ and plateaus at a level approximately 10 -fold higher than normal levels until day 3 [2]. Although macrophages constitute the predominant infiltrating cell population in acutely obstructed kidneys, increased numbers of T lymphocytes are also evident after $24 \mathrm{~h}$ of obstruction though neither B lymphocytes nor neutrophils are observed. Interstitial macrophage numbers further increase at $96 \mathrm{~h}$ after ureteral ligation such that the degree of macrophage infiltration at 14 days is much greater than that at 5 days after obstruction [3]. Thus, the number of interstitial macrophages increases biphasically with an initial rapid increase during the first $24 \mathrm{~h}$ after UUO and the second phase following $72 \mathrm{~h}$ after UUO. This biphasic pattern suggests that discussion of the role of interstitial macrophages in obstructed kidneys should take into account the time frame after UUO.

\section{Experimental Manipulations That Affect the Number of Interstitial Macrophages in the Obstructed Kidney}

Various experimental manipulations that affect the interstitial macrophage infiltrate of obstructed kidneys and the consequent effect upon the degree of renal fibrosis provides important information regarding the role of macrophages in renal fibrosis. Since many interstitial macrophages are recruited from circulating monocytes, strategies that limit interstitial macrophage infiltration include systemic monocyte depletion and blockade of the factors that promote monocyte recruitment.

Multiple molecules on the endothelial cell surface and the subendothelial environment direct circulating monocytes to inflamed sites and these include selectins and integrins that mediate monocyte rolling and adhesion followed by diapedesis. Various chemokines that attract monocytes have also been demonstrated on tubular epithelial cells and peritubular capillary endothelial cells and these include monocyte chemoattractant protein-1 (MCP-1) and regulated upon activation, normal T cell expressed and secreted (RANTES). Targeted deletion or blockade of chemokines or chemokine receptors primarily interrupted the initial phase of macrophage infiltration following UUO and resulted in decreased macrophage infiltration and reduced renal fibrosis [12]. Sung et al. [13] used liposome-encapsulated clodronate to systemically deplete macrophages in a rat UUO model. Systemic macrophage depletion resulted in reduced initial interstitial macrophage infiltration and decreased renal fibrosis also in this model. Thus, the results of these studies suggest that the initial phase of macrophage infiltration may promote renal fibrosis.

\section{Possible Functional Heterogeneity of Interstitial Macrophages in the Obstructed Kidney}

Although interrupting the initial phase of macrophage infiltration following UUO results in decreased interstitial fibrosis, a number of studies (summarized in table 1) have indicated an inverse correlation between the number of interstitial macrophages and the degree of fibrosis in obstructive nephropathy thereby suggesting a potential renoprotective role of macrophages in renal fibrosis. We previously reported the inverse correlation between interstitial macrophage number and interstitial fibrosis in mice that had received a bone marrow transplant from angiotensin II type 1 receptor null (Agtr1-/-) mice [3]. We found a similar relationship in mice that either underwent cyclophosphamide-mediated peripheral macrophage depletion [6] or were treated with matrix metalloproteinase (MMP)-2 inhibitor at day 14, but not at day 5, after UUO [8]. In mice reconstituted with Agtr1-/- bone marrow, it has been suggested that the reduced macrophage infiltration and increased renal fibrosis are associated with the impairment of functions such as migration and phagocytosis in Agtr1-/- macrophages [3]. In mice depleted of macrophages by cyclophosphamide treatment, adoptive transfer of bone marrow-derived macrophages ameliorated renal fibrosis [6]. The suppressed macrophage infiltration and accelerated renal fibrosis in mice treated with a MMP-2 inhibitor is associated with decreased macrophage migration towards the degradation products of extracellular matrix (ECM) [8]. In urokinase-type plasminogen activator receptor null ( $u P A R-/-)$ mice, Zhang et al. [4] demonstrated increased renal fibrosis and suppressed macrophage infiltration at day 14 , but not at day 3 , after UUO. They suggested that the absence of scavenging re- 
Table 1. Reports indicating inverse correlation between the number of interstitial macrophages and the degree of fibrosis in obstructive nephropathy

\begin{tabular}{|c|c|c|c|c|c|c|c|}
\hline Treatment & $\begin{array}{l}\text { Duration of } \\
\text { treatment* }\end{array}$ & $\begin{array}{l}\text { Day of } \\
\text { assessment* }\end{array}$ & $\begin{array}{l}\text { Number of inter- } \\
\text { stitial macrophages }\end{array}$ & Degree of fibrosis & $\begin{array}{l}\text { Myofibroblast } \\
\text { accumulation }\end{array}$ & Species & $\begin{array}{l}\text { Reference } \\
\text { No. }\end{array}$ \\
\hline BMT from Agtr1null mice & - & $\begin{array}{l}\text { day } 5 \\
\text { day } 14\end{array}$ & $\begin{array}{l}\text { unchanged } \\
\text { decreased }\end{array}$ & $\begin{array}{l}\text { unchanged } \\
\text { increased }\end{array}$ & $\begin{array}{l}- \\
\text { unchanged }\end{array}$ & mouse & 3 \\
\hline UUO in uPAR gene knockout mice & - & $\begin{array}{l}\text { day } 3 \\
\text { day } 14\end{array}$ & $\begin{array}{l}\text { decreased } \\
\text { decreased }\end{array}$ & $\begin{array}{l}\text { unchanged } \\
\text { increased }\end{array}$ & $\begin{array}{l}\text { increased } \\
\text { increased }\end{array}$ & mouse & 4 \\
\hline Reversal of ureteral obstruction & $\begin{array}{l}\text { R-UUO } \\
\text { at day } 10\end{array}$ & $\begin{array}{l}6 \text { weeks after } \\
\text { R-UUO }\end{array}$ & $\begin{array}{l}\text { unchanged compared } \\
\text { with } 2 \text { weeks after } \\
\text { R-UUO }\end{array}$ & $\begin{array}{l}\text { decreased compared } \\
\text { with } 2 \text { weeks after } \\
\text { R-UUO }\end{array}$ & - & mouse & 5 \\
\hline $\begin{array}{l}\text { Macrophage depletion by cyclophos } \\
\text { phamide treatment }\end{array}$ & $\begin{array}{l}\text { day }-2 \text { to } 1 \\
\text { day } 6 \text { to } 10\end{array}$ & $\begin{array}{l}\text { day } 5 \\
\text { day } 14\end{array}$ & $\begin{array}{l}\text { decreased } \\
\text { decreased }\end{array}$ & $\begin{array}{l}\text { unchanged } \\
\text { increased }\end{array}$ & - & mouse & 6 \\
\hline $\begin{array}{l}\text { Adoptive macrophage transfer after } \\
\text { cyclophosphamide treatment }\end{array}$ & $\begin{array}{l}\text { day }-2 \text { to } 4 \\
\text { day } 6 \text { to } 11\end{array}$ & $\begin{array}{l}\text { day } 5 \\
\text { day } 14\end{array}$ & $\begin{array}{l}\text { increased } \\
\text { increased }\end{array}$ & $\begin{array}{l}\text { unchanged } \\
\text { decreased }\end{array}$ & & & \\
\hline $\begin{array}{l}\text { Administration of low-molecular- } \\
\text { weight heparin }\end{array}$ & day 0 to 14 & day 14 & increased & decreased & - & rat & 7 \\
\hline Administration of MMP-2 inhibitor & $\begin{array}{l}\text { day }-2 \text { to } 4 \\
\text { day } 7 \text { to } 13\end{array}$ & $\begin{array}{l}\text { day } 5 \\
\text { day } 14\end{array}$ & $\begin{array}{l}\text { unchanged } \\
\text { decreased }\end{array}$ & $\begin{array}{l}\text { increased } \\
\text { increased }\end{array}$ & - & mouse & 8 \\
\hline
\end{tabular}

$\mathrm{BMT}=$ Bone marrow transplantation; Agtrl = angiotensin II type 1 receptor; $\mathrm{uPAR}=$ urokinase-type plasminogen activator receptor; R-UUO = reversal of unilateral ureteral obstruction; MMP-2 = matrix metalloproteinases-2. * The day of ureteral ligation was day 0.

ceptor of $u P A R-/-$ macrophages resulted in the delayed clearance of pro-fibrotic molecules. In a mouse model of reversal of ureteral obstruction (R-UUO), Cochrane et al. [5] reported that although interstitial matrix expansion and kidney collagen concentration was markedly decreased at 6 weeks following reversal, interstitial macrophage infiltration still persisted at a level comparable with that of 2 weeks after R-UUO. In this study, significant numbers of macrophages were associated with areas of active remodeling in the kidneys after R-UUO suggesting a role for macrophages in both renal injury and repair. Additionally, Pecly et al. [7] reported that administration of low molecular weight heparin in the rat UUO model reduced collagen content and was associated with an increased number of infiltrating macrophages in the obstructed kidney 14 days after UUO. They suggested an effect upon the activation of heparin-binding proteins expressed by circulating monocytes or the macrophage chemotactic factor midkine that is expressed by tubular epithelial cells in the diseased kidney. In all of these reports, the inverse correlation between interstitial macrophage number and the degree of fibrosis was noted at the later stage of UUO (day 14) and we should therefore consider the possible renoprotective role for macrophages that infiltrate in the later phase after UUO.

Macrophage Phenotype and Renal Fibrosis

\section{Interstitial Macrophages as Regulators of Inflammatory and Fibrotic Processes}

Recent work indicates that macrophages can be functionally distinguished into two broad phenotypes based on cell surface markers and cytokine profile and this has implications for the role of macrophages in inflammation and fibrosis [9-11]. Classically activated (M1) macrophages are induced by the Th-1 lymphokine interferon (IFN)- $\gamma$, bacterial and fungal cell wall components or degraded matrix. In contrast, alternatively activated (M2) macrophages are induced by Th-2 lymphokines such as interleukin (IL)4 , IL-10, IL-13 and transforming growth factor (TGF)- $\beta$, anti-inflammatory agents such as corticosteroids as well as the phagocytosis of apoptotic cells [14]. M1 and M2 macrophages mediate contrasting and complementary functions in tissue fibrosis. For example, M1 macrophages may induce apoptosis of host tissue cells through the release of proinflammatory mediators such as tumor necrosis factor (TNF)- $\alpha$ [15] and nitric oxide (NO) in rodents [16] thereby inducing tissue injury. Indeed, tubular epithelial cells represent a target of macrophage-induced apoptosis in the obstructed kidney [17]. Apoptotic cells are rapidly recognized and phagocytosed by macrophages with this process promoting differentiation into M2 macrophages $[15,18]$. Macrophages reprogrammed by apoptotic cell ingestion or ex- 


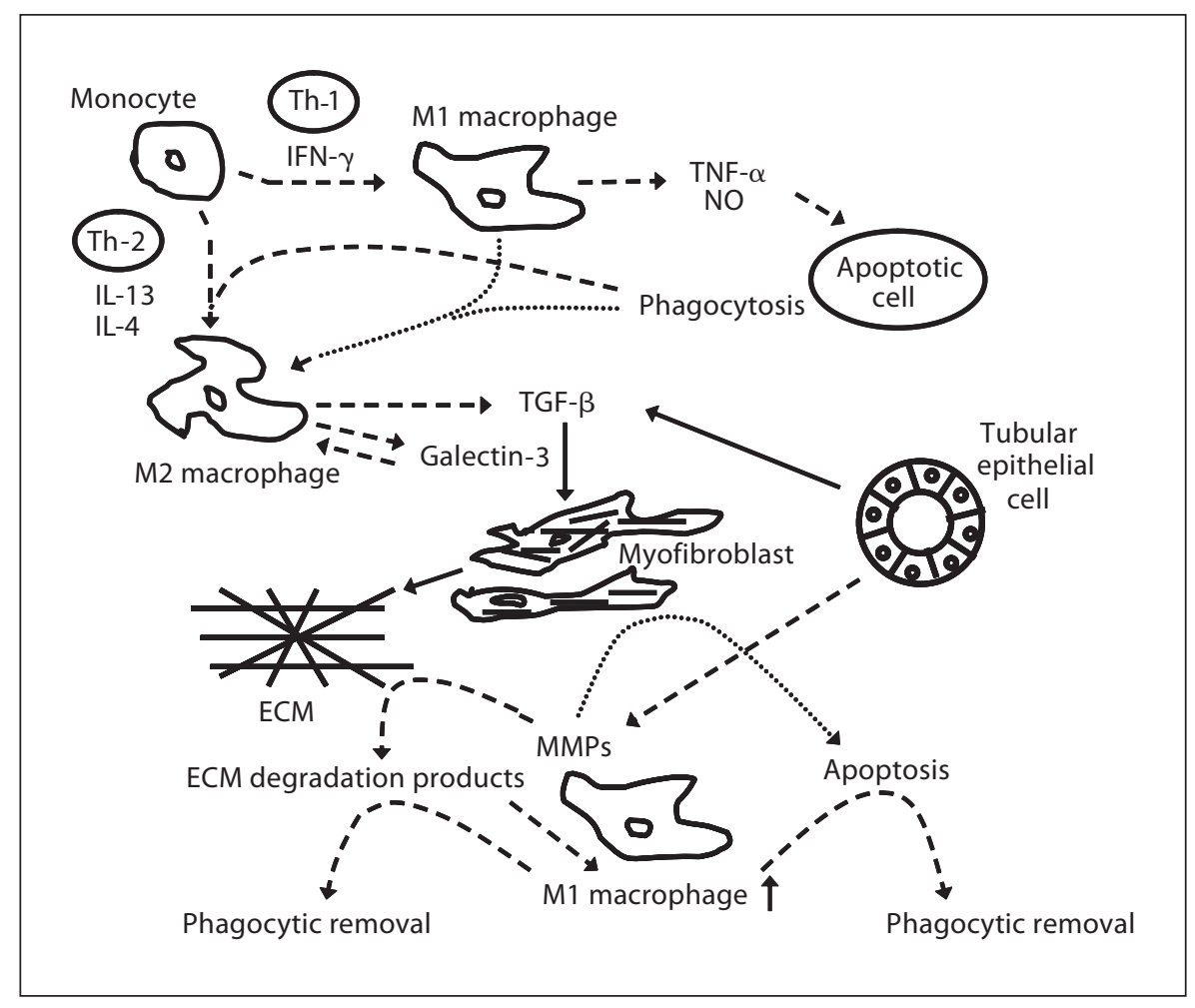

Fig. 1. Schematic representation of the proposed roles of macrophages in renal fibrosis of obstructed kidneys. Recruited monocytes differentiate into M1 (classically activated) macrophages following stimulation of cytokines such as IFN- $\gamma$. M1 macrophages produce pro-inflammatory mediators (TNF- $\alpha, N O)$ that may induce tubular epithelial cell apoptosis and tissue injury. The differentiation of M2 (alternatively activated) macrophages may be induced by apoptotic cell phagocytosis or cytokines such as IL13 or IL-4. Apoptotic cell phagocytosis by M1 macrophages modulates their phenotype and generates macrophages with many features of M2 macrophages. M2 macrophages generate anti-inflam- matory cytokines such as TGF- $\beta$ and galectin-3 that result in myofibroblast activation, proliferation and ECM deposition. ECM accumulation and matrix degradation products stimulate monocyte recruitment and its differentiation to M1 macrophages that produce MMPs that can promote ECM degradation and potentially induce apoptosis of myofibroblasts. Tubular epithelial cells may also produce TGF- $\beta$ and MMPs. Solid arrows indicate the mechanisms that have been reported in the UUO model, dashed arrows indicate the mechanisms that have been reported in vitro or in vivo, but not in the UUO model whilst dotted arrows indicate the mechanisms that are currently unclear. posure to anti-inflammatory cytokines act to dampen inflammation by the secretion of cytokines such as IL-10 and TGF- $\beta$ and appear to be highly pro-fibrogenic and contribute to tissue remodeling where increased ECM deposition predominates. Indeed, M2 macrophages produce large amounts of TGF- $\beta$ [18] and can induce myofibroblast proliferation [19]. In contrast, M1 macrophages produce MMPs $[19,20]$ and can also induce myofibroblasts to produce MMPs [21] that promotes ECM degradation and facilitates the resolution of fibrosis. Furthermore, MMPs may contribute to the resolution of fibrosis by stimulating myofibroblast apoptosis [22]. As depicted in table 1, $u P A R-/-$ mice exhibit increased myofibroblast accumulation and fibrosis that is accompanied with decreased macrophage infiltration at a late stage after UUO [4], suggest- ing that infiltrating macrophages may exert anti-fibrotic actions by affecting the size of the interstitial myofibroblast population. Although MMPs may induce basement membrane injury and promote epithelial-mesenchymal transdifferentiation (EMT) of renal tubular cells and renal fibrosis [23], it is of interest that early inhibition of MMP-2 activity in experimental allograft nephropathy ameliorated fibrosis whereas MMP-2 inhibition in the setting of established fibrosis resulted in more severe allograft nephropathy [24]. Thus, this stimulation of the production of MMPs by M1 macrophages during the later stages of fibrosis may shift the equilibrium towards degradation and play an important anti-fibrotic role.

Although the contribution of these two phenotypes of macrophages at each stage of the fibrotic process still re- 
mains to be elucidated, a recent study by Duffield et al. [25] used a conditional monocyte/macrophage ablation system to confirm the presence of two distinct macrophage phenotypes in progressive and resolving liver fibrosis in mice treated with $\mathrm{CCl}_{4}$. Macrophage depletion during progressive inflammatory fibrosis ameliorated scarring and reduced myofibroblast numbers whilst macrophage depletion during the recovery phase led to a failure of matrix degradation and persistent scarring.

Recent reports indicate that macrophage-derived galectin-3 is required for TGF- $\beta$-mediated myofibroblast activation and matrix production in hepatic fibrosis [26] and obstructive nephropathy [27]. Furthermore, classical macrophage activation with IFN- $\gamma$ and lipopolysaccharide inhibits galectin-3 expression whereas galectin-3 is expressed and released by macrophages with M2 phenotypic markers with galectin-3 promoting M2 macrophage activation [28]. Thus, macrophages may regulate tissue fibrosis via galectin-3 with the production of galectin-3 being distinctively regulated by the phenotype of macrophages.

\section{Conclusions}

Although macrophages have classically been recognized as an active player in progressive renal scarring, several recent studies have suggested a renoprotective role of infiltrating macrophages that preserves renal architecture and limits progressive renal scarring in the late stage after UUO. These seemingly paradoxical findings may reflect the differential regulation of inflammation and fibrosis by two functionally distinct phenotypes of macrophages (summarized in fig. 1). Several specific markers for each macrophage phenotype have recently reported e.g. Ym1 (chitinase-like lectin) and RELM- $\alpha$ (resistin-like secreted protein - also known as FIZZ1 [found in inflammatory zone 1]) are markers of M2 macrophages [29]. These distinct phenotypes of macrophages require consideration in the analysis of the mechanism and, more importantly, therapeutic approaches to renal fibrosis. For example, novel therapeutic agents that specifically target either M1 or M2 macrophages may represent a more selective approach for renal fibrosis. The inhibition of M2 macrophages during progressive fibrosis would be predicted to decrease the fibrotic response and recent studies examining the mechanisms that regulate alternative macrophage activation may provide new therapeutic targets. Also, since M1 macrophages may be anti-fibrotic, attempts to convert M2 macrophages to a M1 phenotype might be helpful. A caveat with this potential approach is that agents used to stimulate the M1 phenotype are pro-inflammatory and may induce tissue injury. There is now a need to develop novel therapies that modulate macrophage function to treat renal fibrosis.

\section{References}

-1 Eddy AA: Interstitial macrophages as mediators of renal fibrosis. Exp Nephrol 1995;3: 76-79.

-2 Schreiner GF, Harris KPG, Purkerson ML, Klahr S: Immunological aspects of acute ureteral obstruction: Immune cell infiltrate in the kidney. Kidney Int 1988;34:487-493.

$\checkmark 3$ Nishida M, Fujinaka H, Matsusaka T, Price J, Kon V, Fogo AB, Davidson JM, Linton MF, Fazio S, Homma T, Yoshida H, Ichikawa I: Absence of angiotensin II type 1 receptor in bone marrow-derived cells is detrimental in the evolution of renal fibrosis. J Clin Invest 2002;110:1859-1868.

4 Zhang G, Kim H, Cai X, Lopez-Guisa JM, Carmeliet P, Eddy AA: Urokinase receptor modulates cellular and angiogenic responses in obstructive nephropathy. J Am Soc Nephrol 2003;14:1234-1253.
5 Cochrane AL, Kett MM, Samuel CS, Campanale NV, Anderson WP, Hume DA, Little $\mathrm{MH}$, Bertram JF, Ricardo SD: Renal structural and functional repair in a mouse model of reversal of ureteral obstruction. J Am Soc Nephrol 2005;16:3623-3630.

6 Nishida M, Okumura Y, Fujimoto S, Shiraishi I, Itoi T, Hamaoka K: Adoptive transfer of macrophages ameliorates renal fibrosis in mice. Biochem Biophys Res Commun 2005; 332:11-16.

7 Pecly IM, Gonçalves RG, Rangel EP, Takiya CM, Taboada FS, Martinusso CA, Pavão MSG, Leite M Jr: Effects of low molecular weight heparin in obstructed kidneys: decrease of collagen, fibronectin and TGF- $\beta$, and increase of chondroitin/dermatan sulfate proteoglycans and macrophage infiltration. Nephrol Dial Transplant 2006;21:12121222.
8 Nishida M, Okumura Y, Ozawa S, Shiraishi I, Itoi T, Hamaoka K: MMP-2 inhibition reduces renal macrophage infiltration with increased fibrosis in UUO. Biochem Biophys Res Commun 2007;354:133-139.

$\checkmark 9$ Duffield JS: The inflammatory macrophage: a story of Jekyll and Hyde. Clin Sci 2003;104: 27-38.

10 Lupher Jr ML, Gallatin WM: Regulation of fibrosis by the immune system. Adv Immunol 2006;89:245-288.

11 Ferenbach D, Kluth DC, Hughes J: Inflammatory cells in renal injury and repair. Sem Nephrol 2007;27:250-259.

12 Wada T, Furuichi K, Sakai N, Iwata Y, Kitagawa K, Ishida Y, Kondo T, Hashimoto H, Ishiwata Y, Mukaida N, Tomosugi N, Matsushima K, Egashira K, Yokoyama H: Gene therapy via blockade of monocyte chemoattractant protein-1 for renal fibrosis. J Am Soc Nephrol 2004;15:940-948. 
$\checkmark 13$ Sung SA, Jo SK, Cho WY, Won NH, Kim HK: Reduction of renal fibrosis as a result of liposome encapsulated clodronate induced macrophage depletion after unilateral ureteral obstruction in rats. Nephron Exp Nephrol 2007; 105:e1-e9.

14 Goerdt S, Orfanos CE: Other functions, other genes: alternative activation of antigenpresenting cells. Immunity 1999;10:137142.

15 Duffield JS, Ware CF, Ryffel B, Savill J: Suppression by apoptotic cells defines tumor necrosis factor-mediated induction of glomerular mesangial cell apoptosis by activated macrophages. Am J Pathol 2001;158:13971404.

16 Kipari T, Hughes J: Macrophage-mediated renal cell death. Kidney Int 2002;61:760761.

17 Lange-Sperandio B, Cachat F, Thornhill BA, Chevalier RL: Selectins mediate macrophage infiltration in obstructive nephropathy in newborn mice. 2002;61:516-524.

18 Fadok VA, Bratton DL, Konowal A, Freed PW, Westcott JY, Henson PM: Macrophages that have ingested apoptotic cells in vitro in hibit proinflammatory cytokine production through autocrine/paracrine mechanisms involving TGF- $\beta$, PGE2, and PAF. J Clin Invest $1998 ; 101: 890-898$
19 Song E, Ouyang N, Horbelt M, Antus B, Wang M, Exton MS: Influence of alternatively and classically activated macrophages on fibrogenic activities of human fibroblasts. Cell Immunol 2000;204:19-28.

20 Gibbs DF, Warner RL, Weiss SJ, Johnson KJ Varani J: Characterization of matrix metalloproteinases produced by rat alveolar macrophages. Am J Respir Cell Mol 1999;20: 1136-1144.

21 Mariani TJ, Sandefur S, Robby JD, Pierce RA: Collagenase-3 induction in rat lung fibroblasts requires the combined effects of tumor necrosis factor- $\alpha$ and 12-lipoxygenase metabolites: a model of macrophage-induced, fibroblast-driven extracellular matrix remodeling during inflammatory lung injury. Mol Biol Cell 1998;9:1411-1424.

22 Iredale JP, Benyon RC, Pickering J, McCullen M, Northrop M, Pawley S, Hovell C, Arthur MJ: Mechanism of spontaneous resolution of rat liver fibrosis: hepatic stellate cell apoptosis and reduced hepatic expression of metalloproteinase inhibitors. J Clin Invest 1998;102:538-549.

23 Cheng S, Lovett DH: Gelatinase A (MMP-2) is necessary and sufficient for renal tubular cell epithelial-mesenchymal transformation. Am J Pathol 2003;162:1937-1949.

24 Lutz J, Yao Y, Song E, Antus B, Hamar P, Liu S, Heemann U: Inhibition of matrix metalloproteinases during chronic allograft nephropathy in rats. Transplantation 2005; 79: 655-661
25 Duffield JS, Forbes SJ, Constandinou CM, Clay S, Partolina M, Vuthoori S, Wu S, Lang R, Iredale JP: Selective depletion of macrophages reveals distinct, opposing roles during liver injury and repair. J Clin Invest 2005; 115:56-65.

26 Henderson NC, Mackinnon AC, Farnworth SL, Poirier F, Russo FP, Iredale JP, Haslett C, Simpson K, Sethi T: Galectin-3 regulates myofibroblast activation and hepatic fibrosis. Proc Natl Acad Sci USA 2006;103:50605065.

27 Henderson NC, Mackinnon AC, Farnworth SL, Kipari T, Haslett C, Iredale JP, Liu FT, Hughes J, Sethi T: Galectin-3 expression and secretion links macrophages to the promotion of renal fibrosis. Am J Pathol 2008;172: 288-298.

28 Mackinnon AC, Farnworth SL, Hodkinson PS, Henderson NC, Atkinson KM, Leffler H, Nilsson UJ, Haslett C, Forbes SJ, Sethi T: Regulation of alternative macrophage activation by galectin-3. J Immunol 2008;180: 2650-2658.

-29 Raes G, Noël W, Beschin A, Brys L, de Baetselier P, Hassanzadeh GH: FIZZ1 and Ym as tools to discriminate between differentially activated macrophages. Dev Immunol 2002; 9:151-159. 